Nanoscale

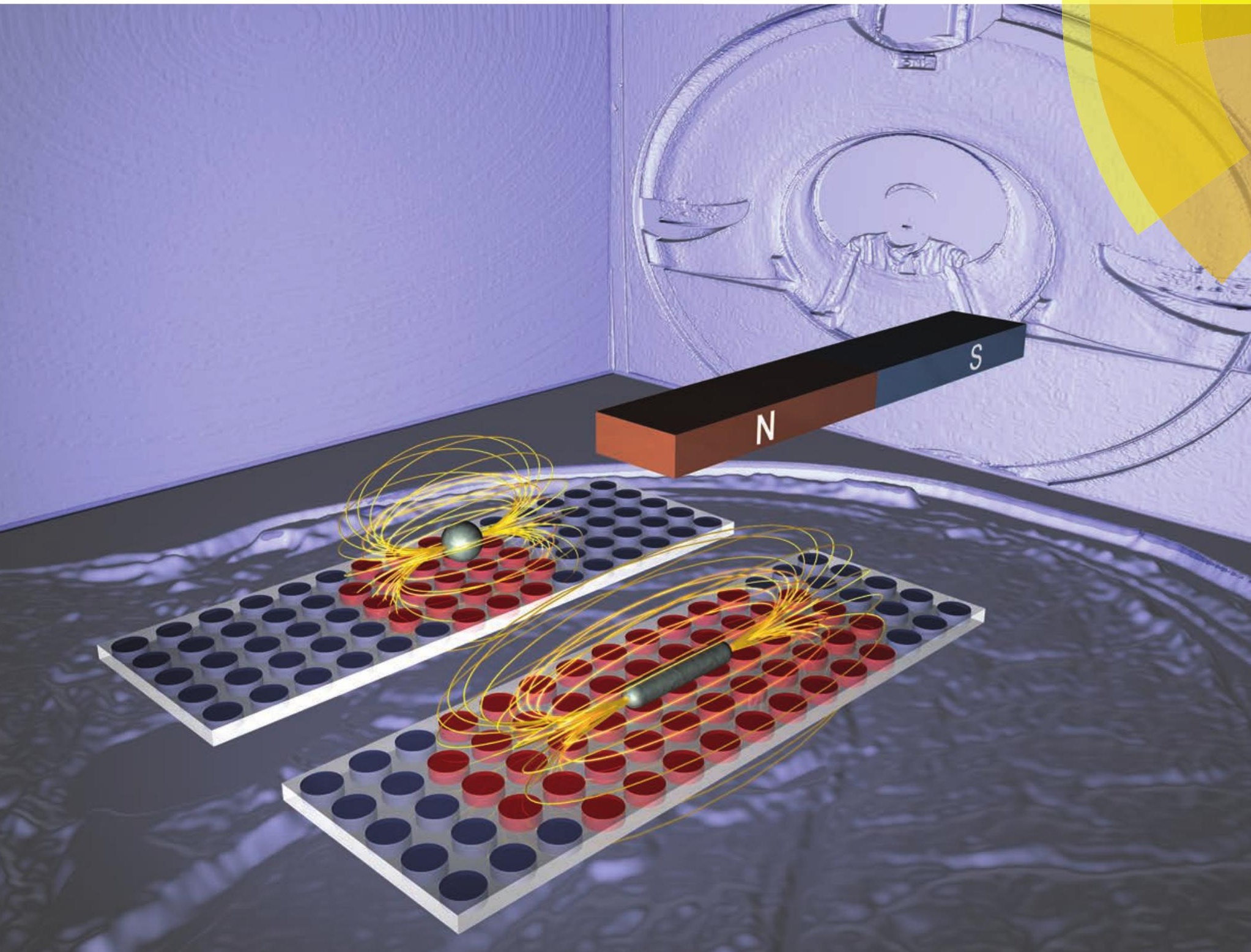

ISSN 2040-3364

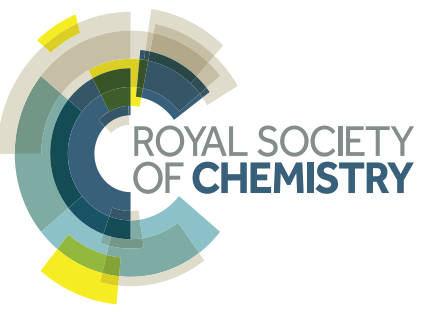

\title{
PAPER
}

D. Bahadur, M. Aslam et al.

Iron oxide nanorods as high-performance magnetic resonance imaging contrast agents 


\title{
Nanoscale
}

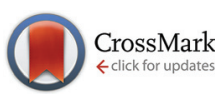

Cite this: Nanoscale, 2015, 7, 9174

\section{Iron oxide nanorods as high-performance magnetic resonance imaging contrast agents $\uparrow$}

\author{
Jeotikanta Mohapatra, ${ }^{a}$ Arijit Mitra, ${ }^{\mathrm{b}}$ Himanshu Tyagi, ${ }^{\mathrm{b}}$ D. Bahadur ${ }^{\star \mathrm{a}, \mathrm{c}}$ and \\ M. Aslam*t;
}

An efficient magnetic resonance imaging (MRI) contrast agent with a high $R_{2}$ relaxivity value is achieved by controlling the shape of iron oxide to rod like morphology with a length of 30-70 nm and diameter of 4-12 nm. $\mathrm{Fe}_{3} \mathrm{O}_{4}$ nanorods of $70 \mathrm{~nm}$ length, encapsulated with polyethyleneimine show a very high $R_{2}$ relaxivity value of $608 \mathrm{mM}^{-1} \mathrm{~s}^{-1}$. The enhanced MRI contrast of nanorods is attributed to their higher surface area and anisotropic morphology. The higher surface area induces a stronger magnetic field perturbation over a larger volume more effectively for the outer sphere protons. The shape anisotropy contribution is understood by calculating the local magnetic field of nanorods and spherical nanoparticles under an applied magnetic field (3 Tesla). As compared to spherical geometry, the induced magnetic field of a rod is stronger and hence the stronger magnetic field over a large volume leads to a higher $R_{2}$ relaxivity of nanorods.

Received 5th January 2015, Accepted 24th February 2015 DOI: $10.1039 / \mathrm{c} 5 \mathrm{nr} 00055 f$ www.rsc.org/nanoscale control of the size, dopant and surface properties of MNPs. ${ }^{3,15-17}$ The size of iron oxide NPs is varied precisely (4-14 $\mathrm{nm}$ ) by controlled crystallization through thermolysis of iron salt in organic surfactants. The magnetization of iron oxide NPs is also tailored by doping various transition metals such as Zn, Ni, Co, and Mn. Since both the surface area and $M_{\mathrm{S}}$ increase with an increase of the NP size, a linear relationship is observed between $R_{2}$ relaxivity $v s$. nanoparticle size. ${ }^{3}$ For example, Cheon et al. found that the $R_{2}$ value of iron oxide NPs gradually increases from $78 \mathrm{mM}^{-1} \mathrm{~s}^{-1}$ to 106,130 and to $218 \mathrm{mM}^{-1} \mathrm{~s}^{-1}$ as the NP size increases from $4 \mathrm{~nm}$ to 6,9 and $12 \mathrm{~nm}$, respectively. ${ }^{18}$ Despite all these improvements, it is further possible to optimize the magnetic properties, surface area and accordingly the $R_{2}$ relaxivity of $\mathrm{Fe}_{3} \mathrm{O}_{4}$ nanoparticles by controlling the shape. The shape anisotropy could induce very strong localized magnetic field inhomogeneity, as the induced magnetic field strength also actively depends on the shape of the MNP, due to the so-called demagnetization effect. ${ }^{19}$ Although the anisotropic NPs have promising advantages over the spherical shape, the use of NPs with an anisotropic configuration has not been well demonstrated in the literature because their preparation is a challenging task as the surface energy favors the formation of spherical nanoparticles. ${ }^{20,21}$

Our group has been exploring new materials with enhanced MR contrast properties over the last few years..$^{22-26}$ To study the effect of shape on MRI contrast enhancement, we have synthesized spherical and faceted irregular (FI) $\mathrm{CoFe}_{2} \mathrm{O}_{4}$ nanostructures via a high temperature solution phase method. ${ }^{22}$ Similar sized FI structures with lower $M_{\mathrm{S}}$ values than the spherical $\mathrm{CoFe}_{2} \mathrm{O}_{4}$ nanostructures show a higher $R_{2}$ value. The 
enhanced contrast properties are attributed to the differences in surface area between spherical and FI nanostructures, which is higher in the case of FI nanostructures. Recently, Zhao et al. demonstrated that octapod $\mathrm{Fe}_{3} \mathrm{O}_{4}$ NPs of an edge length of $30 \mathrm{~nm}$ exhibit an ultra-high $R_{2}$ relaxivity value (679.3 $\pm 30 \mathrm{mM}^{-1} \mathrm{~s}^{-1}$ ) as compared to their spherical counterpart of similar material volume. ${ }^{27}$ The high $R_{2}$ relaxivity of the octapod shaped NPs is believed to be due to their anisotropic shape, which renders a higher surface area than the spherical shape of their counterpart with a similar material volume. The increased surface area allows a greater number of hydrogen nuclei of water in proximity. Therefore, a greater number of neighboring nuclei are disturbed by the dipolar field of the NPs, resulting in faster relaxation. There are also few reports on the MRI contrast characteristics of nanorods (NRs) of paramagnetic compounds such as $\mathrm{Dy}(\mathrm{OH})_{3}, \quad \mathrm{Gd}(\mathrm{OH})_{3}$ and $\beta$-FeOOH. ${ }^{28-30}$ Even though these paramagnetic compounds possess low magnetic moment $\left(<10 \mathrm{emu}^{-1}\right)$, due to higher surface area, their $R_{2}$ relaxivity is found to be comparable to the commercial $\mathrm{Fe}_{3} \mathrm{O}_{4}$ NP contrast agents. Furthermore, as compared to spherical NPs, NRs offer longer blood circulation times, stronger interaction with tumors, enhanced retention at tumor sites and improved targeting efficiency, making them excellent candidates as targeting carriers or MRI contrast agents. ${ }^{31}$ To the best of our knowledge, there is no report on the MR contrast properties of $\mathrm{Fe}_{3} \mathrm{O}_{4}$ NRs.

Herein, we demonstrate a simple two step reaction strategy for the synthesis of uniform 'colloidal' magnetite nanorods (30-70 $\mathrm{nm}$ in length) with very high $R_{2}$ relaxivity values. We found that the relaxation coefficient $\left(R_{2}\right)$ gradually increases from 312 to $608 \mathrm{mM}^{-1} \mathrm{~s}^{-1}$ with an increase in the length of NRs; this increase is a consequence of magnetization enhancement as well as a sharp increase in the surface area due to anisotropic morphology. Although the spherical NPs exhibit higher magnetization than the NRs of the same material volume, a high relaxivity is realized for NRs. The enhanced MR contrast characteristics of NRs correspond to the larger surface area rendered due to the anisotropic morphology.

\section{Experimental section}

\section{a. Preparation of $\beta-\mathrm{FeOOH}$ nanorods}

The rod-shaped $\mathrm{FeOOH}$ nanostructure was prepared by hydrolysis of $\mathrm{FeCl}_{3}$ aqueous solution. In a typical synthesis of $70 \mathrm{~nm}$ length FeOOH NRs, $20 \mathrm{mmol}$ of $\mathrm{FeCl}_{3} \cdot 6 \mathrm{H}_{2} \mathrm{O}$ was added into a round-bottom flask containing $100 \mathrm{ml}$ of deionized water with $0.2 \mathrm{ml}$ polyethyleneimine (PEI). The reaction mixture was heated at $80{ }^{\circ} \mathrm{C}$ under magnetic stirring for $2 \mathrm{~h}$ to obtain a uniform rod-shaped $\mathrm{FeOOH}$ nanostructure. The precipitate was separated by centrifugation and washed several times with deionized water and ethanol. The length of NRs is controlled from 25 to $70 \mathrm{~nm}$ by varying the PEI content to be $2,1.5,1$, $0.5,0.3$ and $0.2 \mathrm{ml}$. Further, a decrease of PEI content to $0.1 \mathrm{ml}$ and below transformed the rod-shape morphology of FeOOH to a spindle shaped structure of length above $100 \mathrm{~nm}$.

\section{b. Preparation of $\mathrm{Fe}_{3} \mathrm{O}_{4}$ nanorods}

$\mathrm{Fe}_{3} \mathrm{O}_{4}$ NRs were synthesized as follows: $500 \mathrm{mg}$ of $\mathrm{FeOOH}$ nanorods and $25 \mathrm{mmol}$ of oleylamine were taken in a three necked round bottom flask. Under a nitrogen atmosphere, the solution was heated to $200{ }^{\circ} \mathrm{C}$ for $4 \mathrm{~h}$. The final product was subjected to magnetic separation and washed with a mixture of hexane and acetone several times to remove any uncoordinated amine molecules. The details of the synthesis approach are depicted in scheme 1. The morphology of NRs was retained even after the reduction at $200^{\circ} \mathrm{C}$.

\section{c. Preparation of $\mathrm{Fe}_{3} \mathrm{O}_{4}$ nanoparticles}

Uniform $\mathrm{Fe}_{3} \mathrm{O}_{4}$ nanoparticles $(\sigma \leq 15 \%)$ were prepared using our previously published protocol. ${ }^{32}$ In a typical synthesis of $6 \mathrm{~nm} \mathrm{Fe}_{3} \mathrm{O}_{4}$ nanoparticles, a mixture of $5 \mathrm{mM}$ of $\mathrm{FeCl}_{2}$ and $25 \mathrm{mM}$ of oleylamine (amine to precursor molar ratio of $5: 1$ ) was heated at $200{ }^{\circ} \mathrm{C}$ under an $\mathrm{N}_{2}$ atmosphere. The size was controlled with a molar ratio of the precursor to amine of $1: 3$ (9 $\mathrm{nm})$ and $1: 7(4 \mathrm{~nm})$, respectively. To further increase the particle size above $9 \mathrm{~nm}$, a seed-mediated growth model was utilized. ${ }^{33}$ For example, the smaller nanoparticles of $6 \mathrm{~nm}$ were first mixed (in a different quantity of $100 \mathrm{mg}$ or $150 \mathrm{mg}$ ) with more precursor materials and the mixture was heated as per the above procedure to achieve $12 \mathrm{~nm}$ and $16 \mathrm{~nm} \mathrm{Fe}_{3} \mathrm{O}_{4}$ nanoparticles, respectively.

\section{d. Surface functionalization towards 'colloidal' suspension}

To use these samples as MRI contrast agents, the as prepared $\mathrm{Fe}_{3} \mathrm{O}_{4}$ NRs were subjected to surface modification with polyethyleneimine (using the ligand exchange approach as depicted in Fig. $\mathrm{S} 1 \dagger$ ). $100 \mathrm{mg}$ of the as prepared $\mathrm{Fe}_{3} \mathrm{O}_{4}$ NRs were dispersed in $10 \mathrm{~mL}$ of toluene and mixed with $10 \mathrm{ml}$ of dimethylformamide (DMF) containing $2 \mathrm{ml}$ of PEI. Under an $\mathrm{N}_{2}$ atmosphere, the mixture was then continuously stirred at $80^{\circ} \mathrm{C}$ for $8 \mathrm{~h}$. After the reaction, the final product was subjected to magnetic separation and washed with ethanol several times to remove uncoordinated PEI molecules. The functionalized nanorods were dispersed in deionized water and taken for phantom MRI imaging. Similarly to NRs, the aqueous suspension of the amine coated nanoparticles is also prepared by surface modification with polyethyleneimine (PEI).

\section{e. Characterization techniques}

$\mathrm{X}$-ray diffraction (XRD) spectra were recorded using an Xpert PANAlytic X-ray diffractometer with $\mathrm{Cu} \mathrm{K} \alpha$ radiation $(\lambda=$ $1.54 \AA$ A). FTIR spectra were recorded on a Bruker, Vertex-80 using a $\mathrm{KBr}$ pellet. The XPS analysis was performed with a Thermo VG Scientific MultiLab, ESCA Probe using Mg K $\alpha(h \nu=$ $1253.6 \mathrm{eV}$ ) as the exciting source for identification of the elements and their oxidation states. The high-resolution transmission electron microscopy images and selected area diffraction patterns were obtained with a JEOL JEM 2100F field emission gun transmission electron microscope (FEG-TEM) at an accelerating voltage of $200 \mathrm{kV}$. Thermogravimetric analysis (TGA) of coated $\mathrm{Fe}_{3} \mathrm{O}_{4}$ NRs was carried out using a Perkin- 

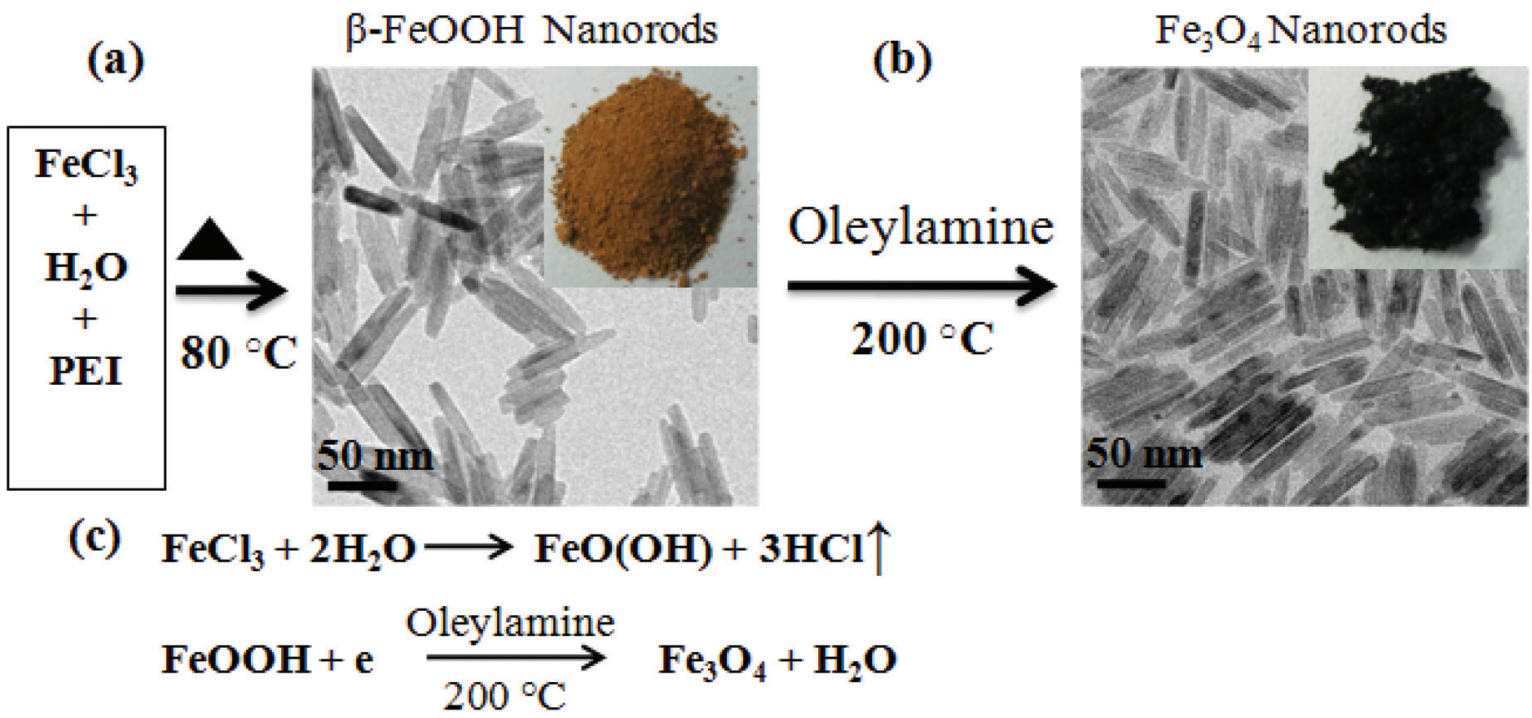

\begin{abstract}
Scheme 1 Schematic representation of the two step synthesis route for $\mathrm{Fe}_{3} \mathrm{O}_{4} \mathrm{NRs}$. (a) Hydrolysis of $\mathrm{FeCl}_{3}(\beta-\mathrm{FeOOH}$, orange colored powder), the corresponding TEM image of the sample confirms that rod shaped $\beta$-FeOOH of uniform sizes were formed with a mean length of $70 \mathrm{~nm}$. (b) FeOOH NRs were reduced to the $\mathrm{Fe}_{3} \mathrm{O}_{4}$ phase using oleylamine as a multifunctional agent (the solvent, reducing and capping agent) at $200{ }^{\circ} \mathrm{C}$; the shape and size of the rods are retained (TEM image). (c) A possible reaction mechanism for the preparation of $\mathrm{Fe}_{3} \mathrm{O}_{4} \mathrm{NRs}$ from FeOOH NRs.
\end{abstract}

Elmer Pyris instrument. TGA measurements were made from room temperature to $600{ }^{\circ} \mathrm{C}$ at a heating rate of $10^{\circ} \mathrm{C} \mathrm{min}^{-1}$. The $\zeta$-potential measurements were carried out by using the Zetasizer nano series, Malvern Instruments. The magnetic properties of the samples were studied using the physical property measurement system (Quantum Design PPMS). The isothermal magnetization $(M)$ versus the applied magnetic field $(H)$, zerofield-cooled (ZFC), and field-cooled (FC) measurements were performed over the temperature range $10-300 \mathrm{~K}$ with an applied field of $40 \mathrm{kOe}$. The applied external field for ZFC and FC magnetization was 200 Oe. To measure the $T_{2}$ relaxivity, the PEI protected $\mathrm{Fe}_{3} \mathrm{O}_{4}$ nanorods with different $\mathrm{Fe}$ concentrations (0.005-0.12) were diluted in DI water. The samples were scanned using a multi-echo $T_{2}$-weighted fast spin echo imaging sequence $(\mathrm{TR} / \mathrm{TE}=3500 / 30,45,60,75,90$ and $105 \mathrm{~ms}$, slice thickness $=2 \mathrm{~mm}$ ) by using a $3 \mathrm{~T}$ Philips Achieva MR scanner.

\section{Results and discussion}

Fig. 1a shows the X-ray diffraction pattern of $70 \mathrm{~nm} \mathrm{FeOOH}$ NRs produced by hydrolysis of $\mathrm{FeCl}_{3}$. All diffraction peaks of $\mathrm{FeOOH}$ are indexed to a tetragonal phase of $\beta$-FeOOH (ICDD 34-1266). Reduction of the $\beta$-FeOOH NRs in oleylamine at $200{ }^{\circ} \mathrm{C}$ transforms the phase to magnetite $\left(\mathrm{Fe}_{3} \mathrm{O}_{4}\right)$ (Scheme 1). The XRD pattern in Fig. 1b confirms the transformation of $\beta$-FeOOH to $\mathrm{Fe}_{3} \mathrm{O}_{4}$. The calculated lattice parameter of $\mathrm{Fe}_{3} \mathrm{O}_{4}$ NRs is $8.39 \AA$, which is in agreement with the reported value (ICDD 19-629). For further confirmation of the magnetite phase formation (and not the maghemite phase), the X-ray photoelectron spectroscopy (XPS) spectrum is recorded after the reduction process (shown as Fig. 1c). The $\mathrm{Fe}_{3} \mathrm{O}_{4}$ nanorods show photoelectron peaks at 711.9 and $725.5 \mathrm{eV}$; the characteristic doublet $\left(\mathrm{Fe} 2 \mathrm{p}_{3 / 2}\right.$ and $\left.\mathrm{Fe} 2 \mathrm{p}_{1 / 2}\right)$ of iron oxide matches very well with the magnetite i.e. $\mathrm{Fe}_{3} \mathrm{O}_{4}$ phase as has been reported in the literature. ${ }^{34,35}$ In the case of $\mathrm{FeOOH}$ nanorods, this doublet appears at 711 and $724.2 \mathrm{eV}$, respectively. In addition, a small characteristic satellite peak of the Fe2p spectrum (octahedral $\mathrm{Fe}^{3+}$ ) of the $\beta$-FeOOH sample appears at $720 \mathrm{eV}$. After phase transformation, this particular peak position shifts to $716 \mathrm{eV}$, a characteristic of $\mathrm{Fe}^{2+}$ presence in the octahedral site of the magnetite phase. ${ }^{34}$ This further confirms the phase conversion from $\beta$ - $\mathrm{FeOOH}$ to $\mathrm{Fe}_{3} \mathrm{O}_{4}$.

FeOOH NRs of different lengths and diameters are produced using PEI as the capping agent (Fig. S2, ESI†). It is found that in the absence of PEI, the prepared sample possesses a spindle shaped morphology with a larger length $(150 \mathrm{~nm})$ and diameter $(35 \mathrm{~nm})$. However, the addition of an appropriate amount of PEI to the reaction mixture leads to the formation of $\mathrm{FeOOH}$ NRs of thinner diameter. The average lengths of NRs obtained are 25, 30, 40, 50, 60 and $70 \mathrm{~nm}$ (standard deviation, $\sigma \leq 20 \%$ ) for $2 \mathrm{ml}, 1.5 \mathrm{ml}, 1 \mathrm{ml}, 0.5 \mathrm{ml}, 0.3 \mathrm{ml}$ and $0.2 \mathrm{ml}$ of PEI, respectively. The effect of PEI amount on the shape, length and diameter of $\mathrm{FeOOH}$ particles is summarized in Table S1 (ESI $\dagger$ ). We have found that by increasing the PEI concentration from 0.2 to $2 \mathrm{ml}$, the length and diameter of the FeOOH NRs can be controlled from 70 to $25 \mathrm{~nm}$ and 12 to $3 \mathrm{~nm}$, respectively. This control over nanorods' length and diameter with the PEI content is due to the adsorption of the protonized PEI on the lateral plane (200) of the nanorods. ${ }^{36,37}$ The NRs produced with $2 \mathrm{ml}$ PEI content ( $25 \mathrm{~nm}$ in length) show poor crystallinity (Fig. S3a and b, ESI $\dagger$ ). When FeOOH NRs are reduced to the $\mathrm{Fe}_{3} \mathrm{O}_{4}$ phase using oleylamine (which is multi- 

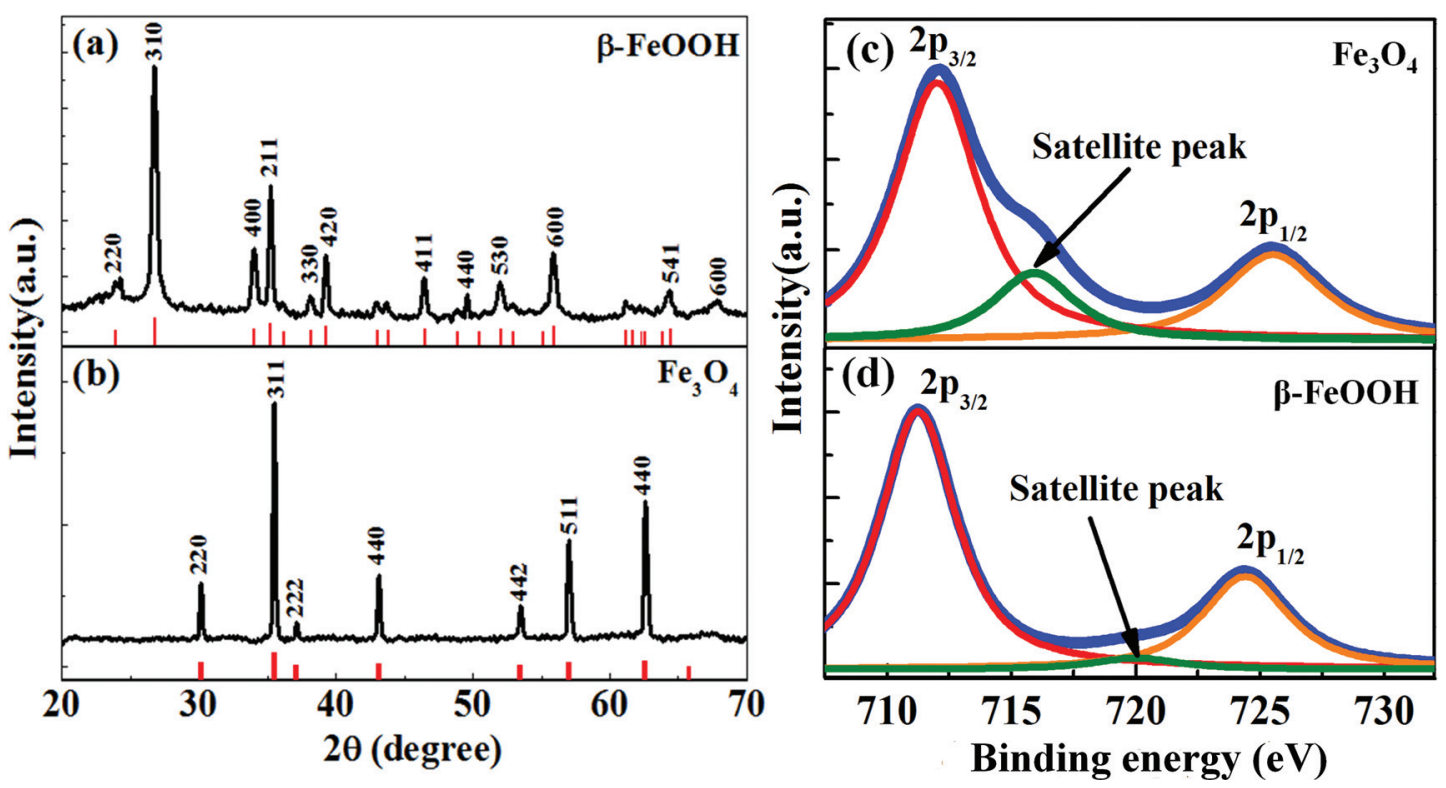

Fig. 1 XRD patterns of (a) the as-synthesized $\beta$ - $\mathrm{FeOOH}$ sample of length $70 \mathrm{~nm}$ and (b) $\mathrm{Fe}_{3} \mathrm{O}_{4} \mathrm{NRs}$ produced after reduction of $\beta$-FeOOH in oleylamine. The XRD patterns of $\beta-\mathrm{FeOOH}$ and $\mathrm{Fe}_{3} \mathrm{O}_{4}$ are labeled with respect to standard ICDD cards (marked as red). The XPS spectra of (c) Fe $\mathrm{O}_{4}$ and (d) $\beta-\mathrm{FeOOH}$ NRs of length $70 \mathrm{~nm}$. After the phase change to $\mathrm{Fe}_{3} \mathrm{O}_{4}$, the characteristic satellite in the octahedral $\mathrm{Fe}^{3+}$ spectrum ( $\beta$-FeOOH NRs) shifts to $716 \mathrm{eV}$ which indicates the presence of $\mathrm{Fe}^{2+}$ in the octahedral site of the magnetite phase. ${ }^{35}$

functional: acts as a solvent, and reducing and capping agent) at $200{ }^{\circ} \mathrm{C}$, the shape and size of the nanorods are retained (Fig. 2a-e). The transformation of the phase ( $\mathrm{FeOOH}$ to $\mathrm{Fe}_{3} \mathrm{O}_{4}$ ) and retention of the rod shape morphology could be due to the multifunctional properties (solvent, surfactant and reductant) of the oleylamine. In this case, oleylamine acts as an electron donor at elevated temperature $\left(200{ }^{\circ} \mathrm{C}\right)$ and leads to the formation of $\mathrm{Fe}_{3} \mathrm{O}_{4}$ nanorods. ${ }^{38}$ However, the $\mathrm{Fe}_{3} \mathrm{O}_{4}$ sample produced from $25 \mathrm{~nm}$ length $\mathrm{FeOOH}$ NRs shows irregular shape and size (Fig. S3c and d, ESI $\dagger$ ). This could be due to the amorphous nature of the initial precursor material (as confirmed from the XRD data), and the reduction process occurs through dissolution and recrystallization of $\mathrm{FeOOH} \mathrm{NRs}^{20}$ Selected area electron diffraction (SAED) measurements are taken to further confirm the crystalline phase of NRs (Fig. 2f). The SAED pattern of $\mathrm{Fe}_{3} \mathrm{O}_{4}$ NRs shows five prominent rings which could be indexed to reflections from the five crystal planes of (220), (311), (400), (511) and (440). ${ }^{32}$ This also supports the transformation of $\mathrm{FeOOH}$ to the $\mathrm{Fe}_{3} \mathrm{O}_{4}$ phase.

Fig. 3a-e shows the transmission electron microscopy (TEM) images of spherical $\mathrm{Fe}_{3} \mathrm{O}_{4}$ nanoparticles of sizes 4, 6, 9, 12 and $16 \mathrm{~nm}$ (standard deviation, $\sigma \leq 15 \%$ ) prepared by thermolysis of $\mathrm{FeCl}_{2}$ in the presence of oleylamine as the multifunctional (solvent, reducing and surface functionalizing) agent. The TEM images confirm that the prepared nanoparticles are uniform in shape and size. The HRTEM image (Fig. 3f) confirms the crystallinity of the as synthesized nanoparticles with $0.251 \mathrm{~nm} d$-spacing corresponding to the [311] plane. Similar to NRs, the aqueous suspensions of the amine coated nanoparticles were also prepared by surface modification with polyethyleneimine (PEI).

To prepare a stable colloidal suspension, the as prepared $\mathrm{Fe}_{3} \mathrm{O}_{4}$ NRs are subjected to surface modification with polyethyleneimine (PEI). The surface PEI molecular coating is confirmed by the Fourier transform infrared (FTIR) spectroscopy, thermogravimetric analysis (TGA) and $\zeta$-potential measurements. Fig. 4a shows a comparative analysis of the FTIR spectra of PEI coated FeOOH $(70 \mathrm{~nm})$, oleylamine and PEI coated $70 \mathrm{~nm} \mathrm{Fe}_{3} \mathrm{O}_{4}$ NRs. In the $\mathrm{FeOOH}$ sample, the low frequency bands at $556,614,695$ and $825 \mathrm{~cm}^{-1}$ were assigned to the $\mathrm{Fe}-\mathrm{O}$ vibrational modes in $\beta$-FeOOH. ${ }^{39}$ After reducing $\mathrm{FeOOH}$ at $200{ }^{\circ} \mathrm{C}$ in oleylamine, these bands disappear and a new peak appears at around $569 \mathrm{~cm}^{-1}$ which corresponds to the $\mathrm{Fe}-\mathrm{O}$ vibrational mode $\left(\mathrm{Fe}^{3+}\right.$ bond) at the octahedral and tetrahedral sites. The presence of a $\mathrm{Fe}-\mathrm{O}$ vibrational mode at $569 \mathrm{~cm}^{-1}$ could be attributed to the magnetite phase of $\mathrm{Fe}_{3} \mathrm{O}_{4}$ since the $\mathrm{Fe}-\mathrm{O}$ band for $\gamma-\mathrm{Fe}_{2} \mathrm{O}_{3}$ is usually seen at $540 \mathrm{~cm}^{-1}$. 32 The strong IR peak in the range of $3745 \mathrm{~cm}^{-1}$ is assigned to the $\mathrm{N}-\mathrm{H}$ stretching mode of the primary amine, while the $\mathrm{C}-\mathrm{N}$ stretching, $\mathrm{NH}_{2}$ scissoring and $\mathrm{NH}_{2}$ wagging bands appear at $1074 \mathrm{~cm}^{-1}, 1447 \mathrm{~cm}^{-1}$ and $885 \mathrm{~cm}^{-1}$, respectively. ${ }^{40}$ The bands at 2845 and $2920 \mathrm{~cm}^{-1}$ are assigned to vibrations from $\mathrm{CH}_{2}$ groups in the long chain of amine. In comparison with oleylamine- $\mathrm{Fe}_{3} \mathrm{O}_{4}$ NRs, the PEI- $\mathrm{Fe}_{3} \mathrm{O}_{4}$ samples show strong IR peaks of C-N stretching, $\mathrm{NH}_{2}$ scissoring and $\mathrm{NH}_{2}$ wagging which corroborate the presence of PEI on the surface of $\mathrm{Fe}_{3} \mathrm{O}_{4}$ NRs. The thermogravimetric degradation profiles (Fig. S4, ESI $\dagger$ ) of the as-prepared and PEI-coated $\mathrm{Fe}_{3} \mathrm{O}_{4}$ NRs show prominent weight loss of $9 \%$ and $15 \%$ over the temperature range of $150-450{ }^{\circ} \mathrm{C}$, 

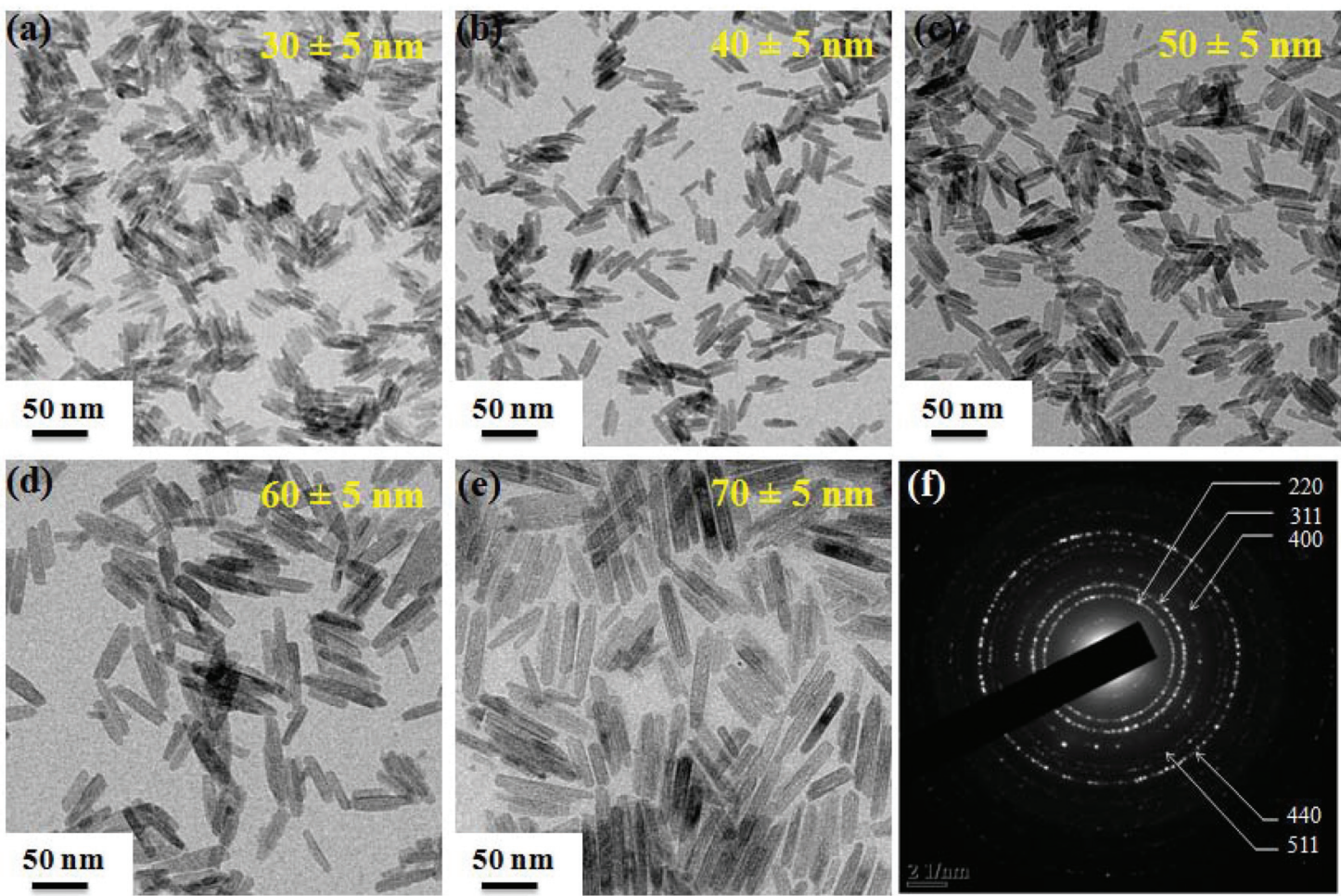

Fig. 2 TEM micrographs of different lengths of $\mathrm{Fe}_{3} \mathrm{O}_{4}$ NRs: (a) $30 \mathrm{~nm}$, (b) $40 \mathrm{~nm}$, (c) $50 \mathrm{~nm}$, (d) $60 \mathrm{~nm}$ and (e) $70 \mathrm{~nm}$. (f) The SAED pattern of $70 \mathrm{~nm}$ $\mathrm{Fe}_{3} \mathrm{O}_{4}$ NRs. The SAED pattern shows a set of rings identified as diffracting from the five crystal planes (220), (311), (400), (511) and (440) of Fe $\mathrm{O}_{4}$.
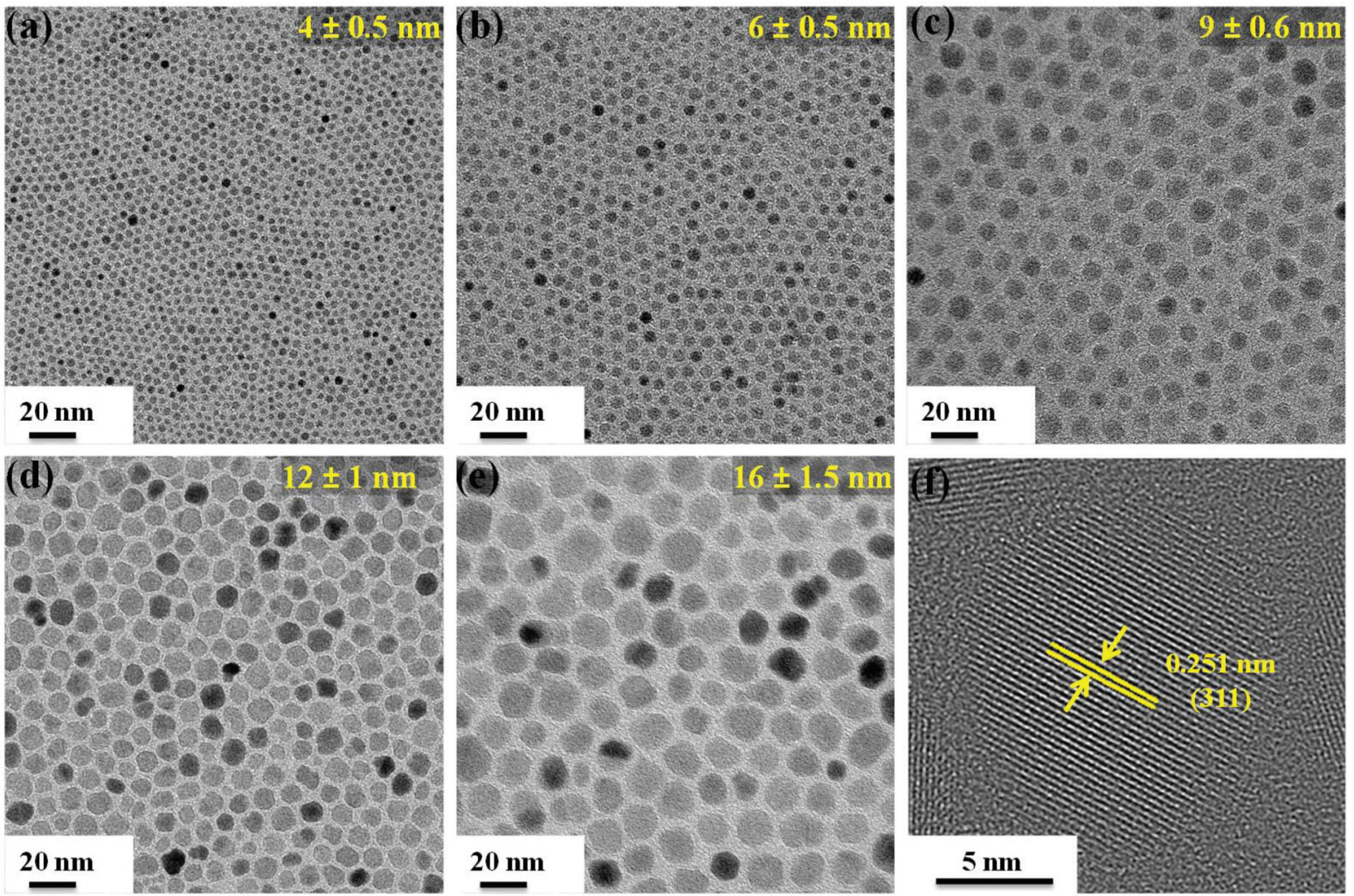

Fig. $3 \mathrm{TEM}$ micrographs of $\mathrm{Fe}_{3} \mathrm{O}_{4}$ nanoparticles produced by thermolysis of $\mathrm{FeCl}_{2}$ and oleylamine at $200{ }^{\circ} \mathrm{C}$ with $\mathrm{Fe}-$ amine mole ratios: (a) $1: 7$ $(4 \mathrm{~nm}),\left(\right.$ b) $1: 5(6 \mathrm{~nm})$, (c) $1: 3(9 \mathrm{~nm})$. (d) $12 \mathrm{~nm}$ and (e) $16 \mathrm{~nm} \mathrm{Fe} \mathrm{O}_{4}$ nanoparticles are obtained from seed-mediated growth using $150 \mathrm{mg}$ and $100 \mathrm{mg}$ of $6 \mathrm{~nm}$ nanoparticles as initial precursors respectively. (f) The HRTEM image of the crystalline $12 \mathrm{~nm} \mathrm{sized} \mathrm{Fe}_{3} \mathrm{O}_{4}$ nanoparticle. 

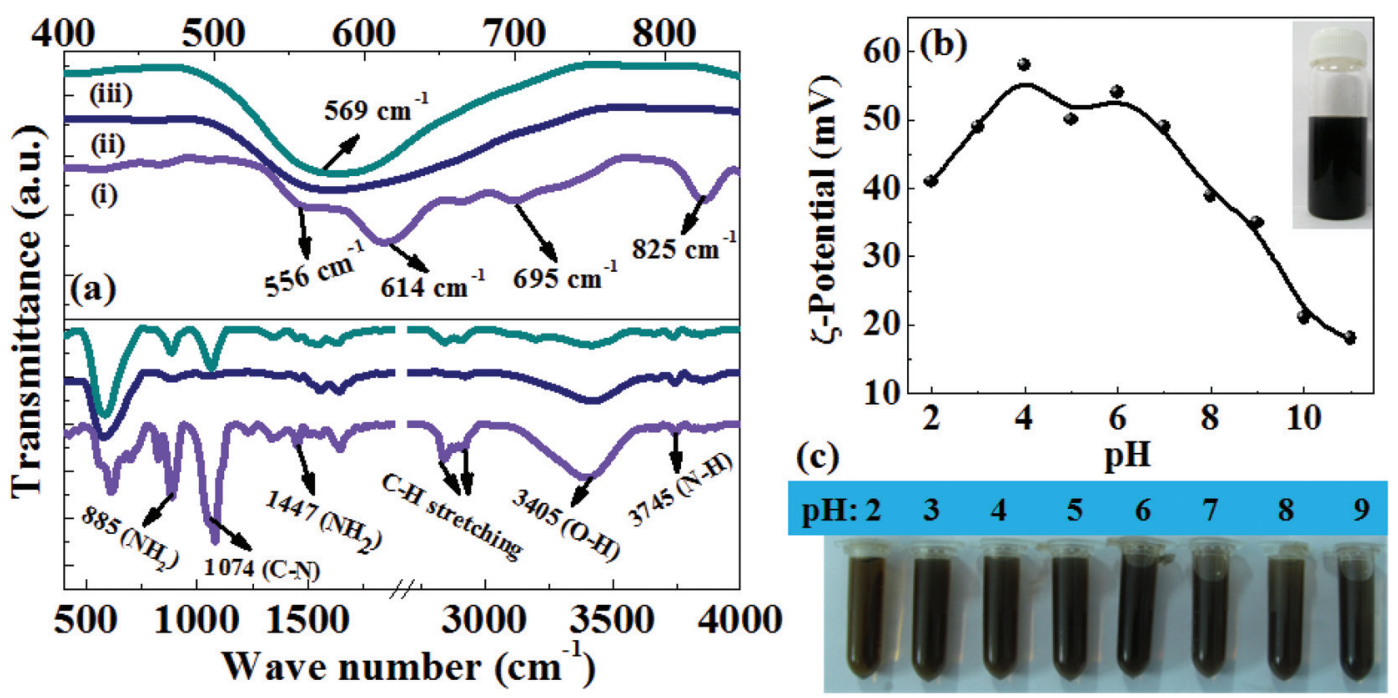

Fig. 4 (a) Comparative analysis of FTIR spectra of the Fe-O vibrations (upper half) and surface functional groups (lower half) of: (i) as prepared PEI coated $\mathrm{FeOOH}$, (ii) oleylamine functionalized $\mathrm{Fe}_{3} \mathrm{O}_{4}$ and (iii) the surface modified $\mathrm{Fe}_{3} \mathrm{O}_{4}$ NRs with PEI. (b) The zeta potential at different pH values of $\mathrm{PEl}$ functionalized $\mathrm{Fe}_{3} \mathrm{O}_{4} \mathrm{NRs}$ and the inset shows the picture of the aqueous suspension of $\mathrm{Fe}_{3} \mathrm{O}_{4} \mathrm{NRs}$ after one month. (c) The digital photograph shows the colloidal stability of $\mathrm{Fe}_{3} \mathrm{O}_{4} \mathrm{NRs}\left(1 \mathrm{mg} \mathrm{ml}^{-1}\right)$ under different $\mathrm{pH}$ conditions.

which could be attributed to the decomposition of the organic molecules attached to the NRs surface. The increase of $6 \%$ weight loss after the surface modification of NRs confirms the presence of PEI on the nanorod surface. Further, the positive zeta potential values in the $\mathrm{pH}$ range $2-11$ (Fig. $4 \mathrm{~b}$ ) also support the presence of the PEI amine groups at the NRs surface. The PEI modified $\mathrm{Fe}_{3} \mathrm{O}_{4}$ NRs are very stable as water colloids for about a month and no aggregation is observed (inset of Fig. $4 \mathrm{~b}$ ). There is no precipitation in water over a wide $\mathrm{pH}$ range ( $\mathrm{pH}$ adjusted between 2 and 9 using $\mathrm{HCl}$ or $\mathrm{NaOH}$ ) (Fig. 4c). Moreover, TEM micrographs show no change in size and shape after the ligand exchange with PEI at a temperature of $80{ }^{\circ} \mathrm{C}$ (Fig. S5, ESI $\dagger$ ). The hydrodynamic diameters of the PEI functionalized $\mathrm{Fe}_{3} \mathrm{O}_{4}$ NRs are measured by dynamic light scattering (DLS: Fig. S6a-c, ESI $\dagger$ ). The mean hydrodynamic diameters (Table S2, ESI $\dagger$ ) are larger than the size obtained using TEM, due to the presence of associated and hydrated long chain PEI layers. ${ }^{41}$ The time dependent DLS study shows that the hydrodynamic size of the NRs does not change over a time frame of one week, indicating no aggregation of NRs. ${ }^{42}$ Such a stable PEI functionalized magnetite NR suspension is highly desirable for a wide range of biomedical applications, as the PEI coating has been found to enhance the nanoparticle uptake into cells and facilitates endosomal escape for the nucleotide delivery. ${ }^{43}$ Further, PEI also has a potential advantage in facilitating DNA and siRNA delivery.

Fig. 5a shows the temperature dependence of the magnetization curve in the zero field cooled (ZFC) and field cooled (FC) protocols under an applied field of 200 Oe for the $\mathrm{Fe}_{3} \mathrm{O}_{4}$ NRs of different sizes. The blocking temperatures $\left(T_{\mathrm{B}}\right)$ (i.e. the peak of the ZFC curve) for $30 \mathrm{~nm}$ and $40 \mathrm{~nm} \mathrm{Fe}_{3} \mathrm{O}_{4}$ NRs are $80 \mathrm{~K}$ and $110 \mathrm{~K}$, respectively. While for NRs of length above $40 \mathrm{~nm}$, the blocking temperature is not observed and the fea- tures of the curve are interestingly dominated by Verwey transition observed at $120 \mathrm{~K}^{44,45}$ Verwey transition is a characteristic property of $\mathrm{Fe}_{3} \mathrm{O}_{4}$ and is seen in perfect stoichiometry. In the case of smaller length NRs, the surface dead layer and surface oxidation makes the NRs sufficiently nonstoichiometric and thus Verwey transition is not observed. Fig. 5b shows the ZFC and FC magnetization data of the spherical nanoparticles of different sizes. With an increase in nanoparticles' size from 4 to $16 \mathrm{~nm}, T_{\mathrm{B}}$ is observed to increase from $45 \mathrm{~K}$ to $240 \mathrm{~K}$. The increase in $T_{\mathrm{B}}$ is attributed to an increase in anisotropic energy with an increase in volume, which is consistent with the expression used to calculate the average blocking temperature $\left\langle T_{\mathrm{B}}\right\rangle=K_{\mathrm{eff}} V / 25 k_{\mathrm{B}}$ (where $k_{\mathrm{B}}$ is the Boltzmann constant and $K_{\text {eff }}$ is the anisotropy constant). ${ }^{46}$ The room temperature hysteresis curves of the $\mathrm{Fe}_{3} \mathrm{O}_{4}$ NRs are shown in Fig. 5c. The coercivity and remanence values are not discernible at $300 \mathrm{~K}$, indicating a superparamagnetic behavior of 30-70 nm length $\mathrm{Fe}_{3} \mathrm{O}_{4}$ NRs. The saturation magnetization $\left(M_{\mathrm{S}}\right.$, magnetization at $\left.40 \mathrm{kOe}\right)$ gradually increases from 50 emu g ${ }^{-1}$ to $66 \mathrm{emu} \mathrm{g}^{-1}$ with an increase in the length of nanorods from $30 \mathrm{~nm}$ to $70 \mathrm{~nm}$. The smaller magnetization values of nanorods as compared to the bulk value $\left(92 \mathrm{emu} \mathrm{g}^{-1}\right.$ for magnetite ${ }^{32}$ ) are believed to be due to the existence of a surface spin disorder layer, which decreases with the increase of the particle diameter. Interestingly, in comparison with NRs, the $M_{\mathrm{S}}$ values of nanoparticles are higher (Fig. $5 \mathrm{~d}$ ). For example, the $M_{\mathrm{S}}$ value for $50 \mathrm{~nm}$ NRs is $58 \mathrm{emu} \mathrm{g}^{-1}$, while that for the same volume of NPs (the volume of a $50 \mathrm{~nm}$ NR is nearly equal to that of $16 \mathrm{~nm}$ NPs, ESI, $\uparrow$ Table S4) is $83 \mathrm{emu}$ $\mathrm{g}^{-1}$. However, from the $M(T)$ curve, we have seen Verwey transition (the bulk phenomenon) in 50-70 nm length NRs, which suggests the absence of a surface oxidized layer. Therefore, we believe that the low magnetization might be due to the surface 

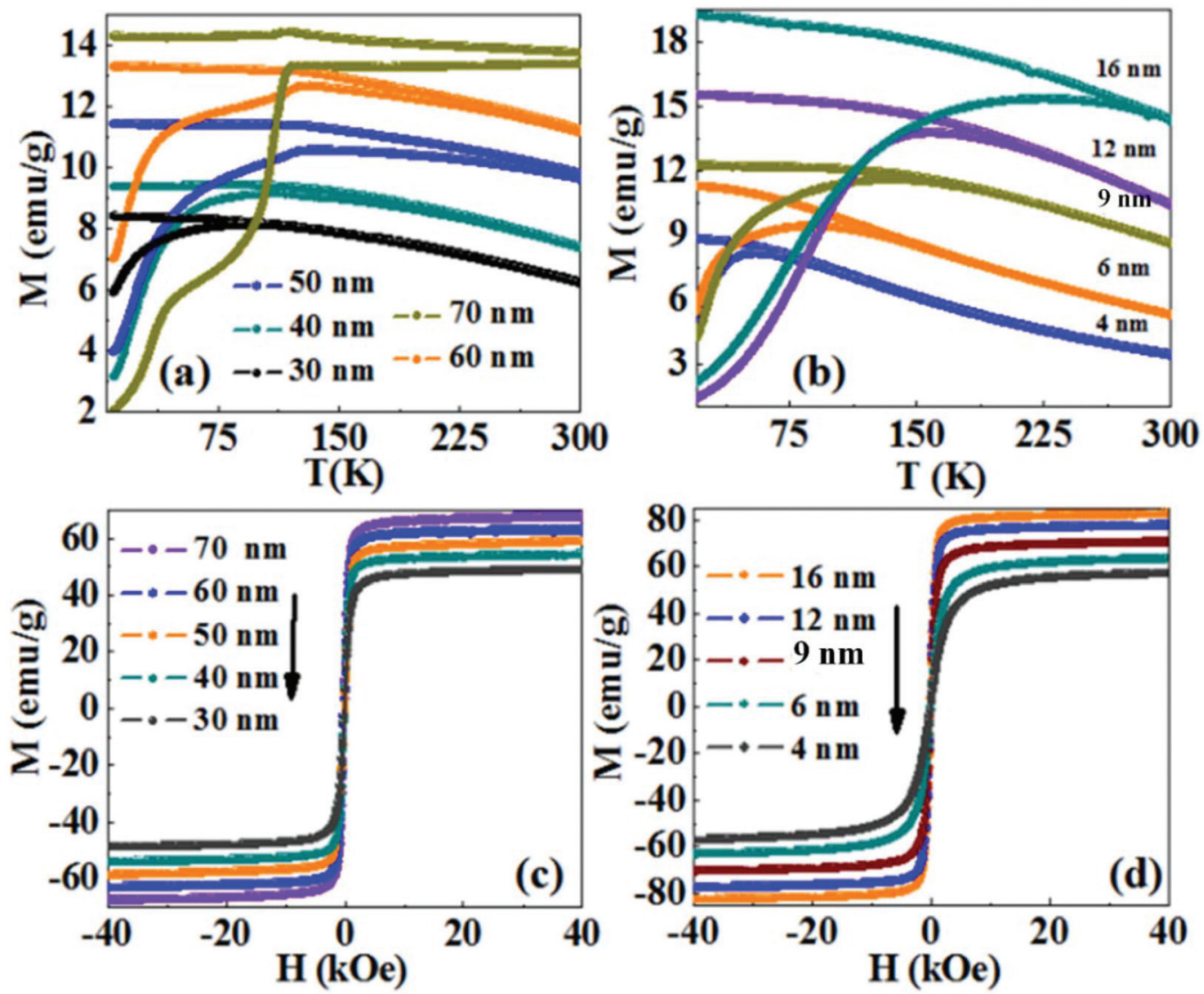

Fig. 5 The field-cooled (FC) and zero-field-cooled (ZFC) magnetization plot of different sizes: (a) nanorods and (b) spherical nanoparticles of Fe ${ }_{3} \mathrm{O}_{4}$ at an applied field of 200 Oe. The room temperature field dependent magnetization curves of different sizes of (c) nanorods and (d) spherical nanoparticles of $\mathrm{Fe}_{3} \mathrm{O}_{4}$.

spin canting as well as the shape anisotropy of the NRs, which prevents them from magnetizing in directions other than along their easy magnetic axis. ${ }^{47}$ For the random orientation of NRs, the projection of the magnetization vectors along the field direction is smaller than that for a collection of nanoparticles without the shape anisotropy effect. ${ }^{48}$

For in vitro applications, the cytocompatibility is investigated using the Sulphorhodamine-B (SRB) assay to assess whether these magnetite NRs have any deleterious biological properties (Fig. S7, ESI†). The SRB assay results indicate that the viability of the HeLa cells is not affected by the mere presence of NRs and the cells register normal growth, suggesting that the NRs are reasonably biocompatible and do not have any toxic effect for in vitro use. The SRB assay shows that nearly $90 \%$ of the cells are viable, even after incubation with $1 \mathrm{mg} \mathrm{ml}^{-1}$ of NRs.

The $T_{2}$ weighted MR images of PEI modified $\mathrm{Fe}_{3} \mathrm{O}_{4}$ NRs and NPs at different iron concentrations are recorded at $3 \mathrm{~T}$. The obtained phantom image shows a significant signal attenuation on increasing the concentration of Fe from 0.005 to $0.12 \mathrm{mmol}$ (Fig. 6a and c). The corresponding relaxation rates $\left(R_{2}=1 / T_{2}\right)$ exhibit a linear trend with the Fe concentration as shown in Fig. $6 \mathrm{~b}$ and $\mathrm{d}$. The $R_{2}$ values for $\mathrm{Fe}_{3} \mathrm{O}_{4}$ NRs with lengths of 30, 40, 50, 60 and $70 \mathrm{~nm}$ are 312, 381, 427, 545 and $608 \mathrm{mM}^{-1} \mathrm{~s}^{-1}$, respectively (Fig. 6b). The increasing trend of $R_{2}$ values with the length of nanorods is possibly due to the enhancement of magnetization value as well as surface area (responsible for the field perturbation areas for the outer sphere protons), which was found to increase with increase of the NRs' length. Fig. 6d shows that $R_{2}$ relaxivity values of $\mathrm{Fe}_{3} \mathrm{O}_{4}$ NPs increase from 141 to $297 \mathrm{mM}^{-1} \mathrm{~s}^{-1}$ with increase in the size from 4 to $16 \mathrm{~nm}$. From the magnetic data, it is observed that the NPs exhibit higher magnetization values as compared to NRs, while the observed $R_{2}$ is counter-intuitive and higher in the case of lower susceptibility nanorods. For example, the $M_{\mathrm{S}}$ value of $16 \mathrm{~nm} \mathrm{Fe}_{3} \mathrm{O}_{4}$ NPs is $83 \mathrm{emu} \mathrm{g}^{-1}$ and that of $50 \mathrm{~nm}$ NRs (equivalent material volume) is $58 \mathrm{emu} \mathrm{g}^{-1}$. Although the $M_{\mathrm{S}}$ value of NRs is less than that of NPs by $25 \mathrm{emu} \mathrm{g}^{-1}$, the NRs exhibit nearly 1.5 times higher $R_{2}$ value. Similarly, the 9 and $12 \mathrm{~nm}$ NPs have material volumes equivalent to those of 30 and $40 \mathrm{~nm}$ length NRs, respectively. However, the $R_{2}$ values of NPs $\left(9 \mathrm{~nm}, 218 \mathrm{mM}^{-1} \mathrm{~s}^{-1}\right.$ and $\left.12 \mathrm{~nm}, 249 \mathrm{mM}^{-1} \mathrm{~s}^{-1}\right)$ are much lower than the NRs $\left(30 \mathrm{~nm}, 312 \mathrm{mM}^{-1} \mathrm{~s}^{-1}\right.$ and $40 \mathrm{~nm}$, $381 \mathrm{mM}^{-1} \mathrm{~s}^{-1}$ ). The difference in $R_{2}$ values between NRs and NPs of equivalent material volumes can be understood by considering the outer sphere theory, which comprises the 

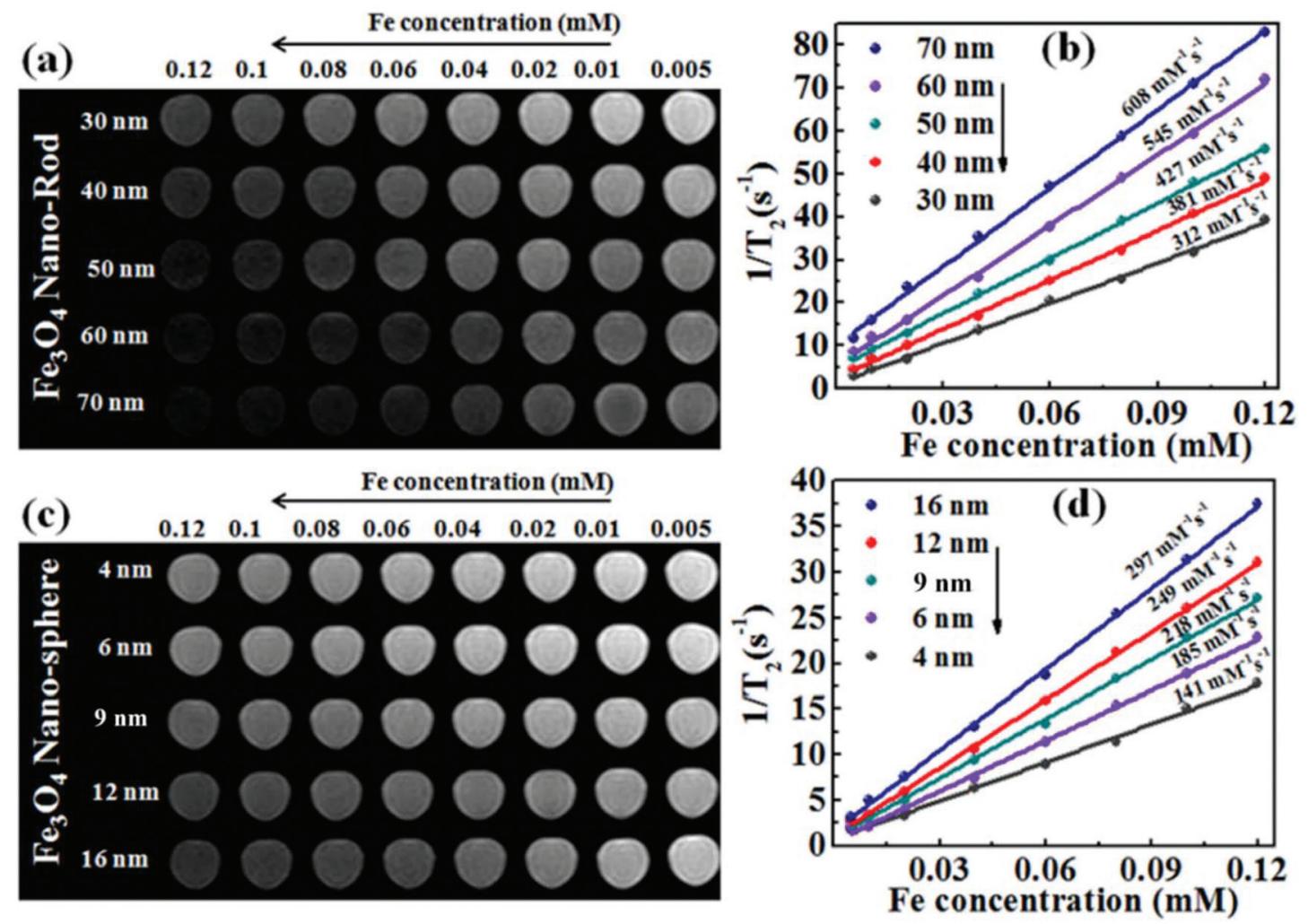

Fig. 6 The MR contrast effect of $\mathrm{Fe}_{3} \mathrm{O}_{4}$ NRs of different lengths and NPs of different diameters. $\mathrm{T}_{2}$-weighted $\mathrm{MR}$ images of Fe $\mathrm{O}_{4}$ (a) $\mathrm{NRs}$ and (c) NPs at various concentrations of iron under an applied magnetic field of $3 \mathrm{~T}, \mathrm{TR}=3500 \mathrm{~ms}$ and TE $=30 \mathrm{~ms}$. Plots of $R_{2}$ values of (b) Fe $\mathrm{O}_{4} \mathrm{NRs}$ and (d) $\mathrm{Fe}_{3} \mathrm{O}_{4} \mathrm{NPs}$ of different sizes.

diffusion and dephasing of protons around the magnetic field inhomogeneity of a magnetic nanoparticle. According to Hwang and Freed's theory, the $R_{2}$ value is proportional to the square of $M_{\mathrm{S}}$ and the effective magnetic diameter (eqn (S1), ESI $\dagger$ note A). ${ }^{27}$ In general, the $M_{\mathrm{S}}$ value determines the local magnetic field inhomogeneity, and the effective diameter defines the field perturbation area for the outer sphere protons. The field perturbation area is directly related to the surface area of nanostructures, and in our case, the NRs possess a higher surface area than NPs of a similar solid volume (Table S4†). For example, the surface area of NRs of length $50 \mathrm{~nm}$ is nearly 1.5 times higher than the surface area of NPs of size $16 \mathrm{~nm}$ which has an equivalent material volume. Therefore, the NRs are considered to be able to generate a larger area of local field inhomogeneity as compared to NPs under an applied magnetic field. The local magnetic field generated by $9-16 \mathrm{~nm}$ NPs and $30-70 \mathrm{~nm}$ length NRs are calculated using Comsol Multiphysics. Fig. 7a-f shows the local magnetic field distribution outside the NPs and NRs of equivalent material volume at an applied magnetic field of 3 Tesla (the magnetic field distribution profile for NRs of length 60 and $70 \mathrm{~nm}$ are shown in Fig. S8, ESI†). The simulation results show a significantly stronger local field inhomogeneity created by the NRs than the NPs. Moreover, from the surface and further away the field intensity decreases slower for NRs than the NPs (Fig. 7g-i), which could be due to an anisotropic shape of the NRs. In general, the magnetic field induced outside a magnetized sphere varies with $\left(1 / r^{3}\right)$, while in the case of a cylinder it varies with $\left(1 / r^{2}\right)$, where ' $r$ ' is the distance away from the surface of the spherical/cylindrical rod object. ${ }^{49}$ Thus, the rod shape morphology and higher outer sphere diameter of the NRs render a strong local magnetic field over a larger volume as compared to NPs, although it possesses lower magnetic moment. As a result, a larger number of water protons experience a strong magnetic field over a large volume and rapidly de-phase, consequently a higher $R_{2}$ value is realized for NRs than for the NPs of equivalent material volume. While for spherical NPs, due to the small volume of magnetic field variations, the water protons slowly diffuse around the nanoparticles and hence slowly de-phase, consequently a smaller $R_{2}$ value is observed. Details of the water proton $R_{2}$ relaxation due to NPs and NRs are shown in Scheme 2. Further, with an increase of NR length, the induced local magnetic field strength outside the NRs also increases (Fig. S8, ESI†) (this enhancement of local magnetic field strength is due to the increase of both the $M_{\mathrm{S}}$ value and the surface area). As a result, with an increase of NR length from 30 to $70 \mathrm{~nm}$, the $R_{2}$ relaxivity value increases linearly from 312 to $608 \mathrm{mM}^{-1} \mathrm{~s}^{-1}$ (Fig. 8a). A similar increasing trend in the $R_{2}$ relaxivity values is also observed for nanoparticles (Fig. 8b). 

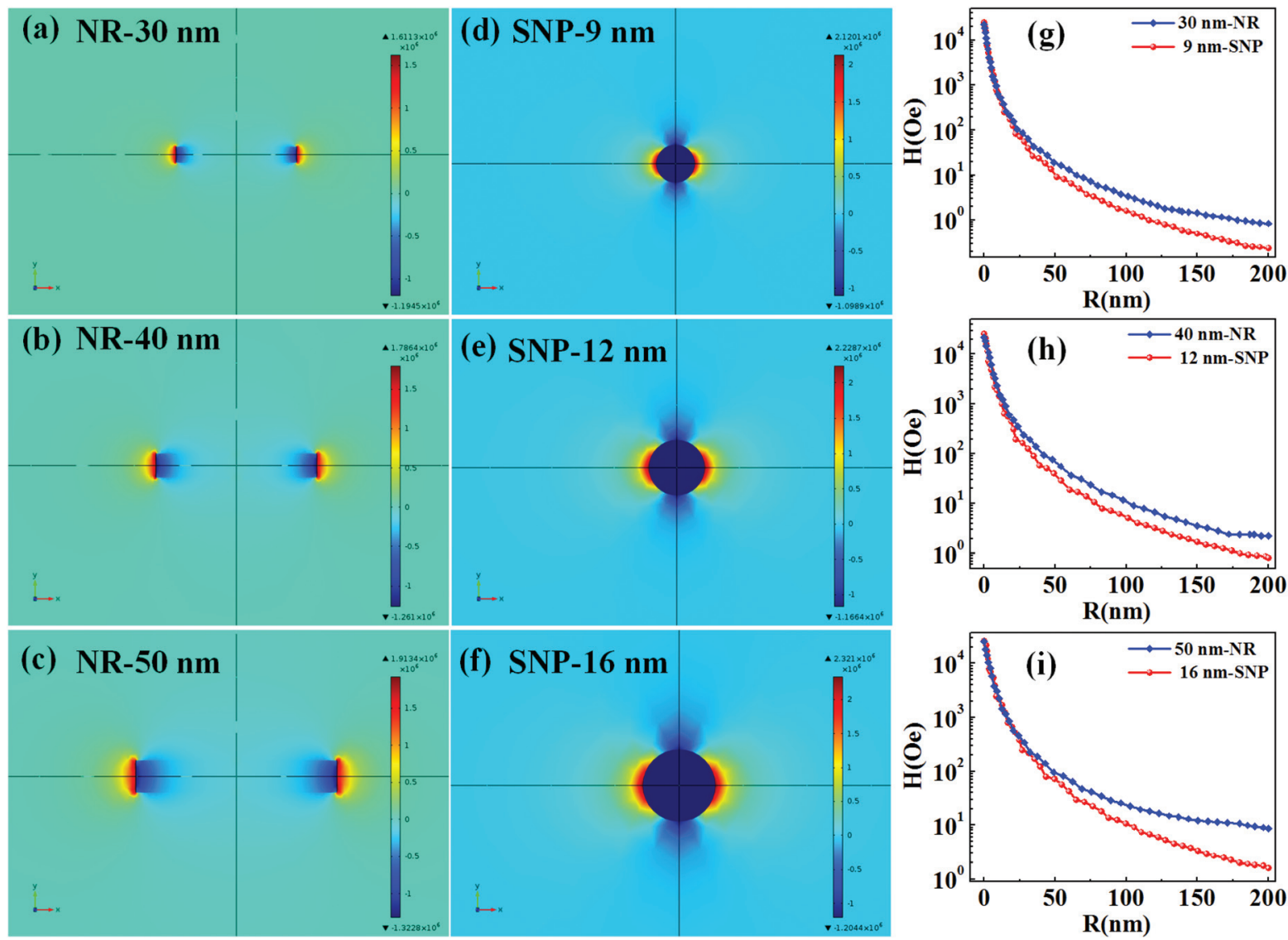

Fig. 7 The local magnetic field generated by the NRs and spherical $\mathrm{Fe}_{3} \mathrm{O}_{4} \mathrm{NPs}$ of equivalent material volumes under an applied magnetic field of 3 T. (a), (b) and (c) show the induced magnetic field distribution of 30, 40 and $60 \mathrm{~nm}$ iron oxide NRs and (d), (e) and (f) show the field distribution of the equivalent material volume NPs of size 9,12 and $16 \mathrm{~nm}$, respectively and (g), (h) and (i) show the variation of induced magnetic field with the distance ' $R$ ' from the surface of NPs and NRs ( $y$-axis is represented at the log-scale).

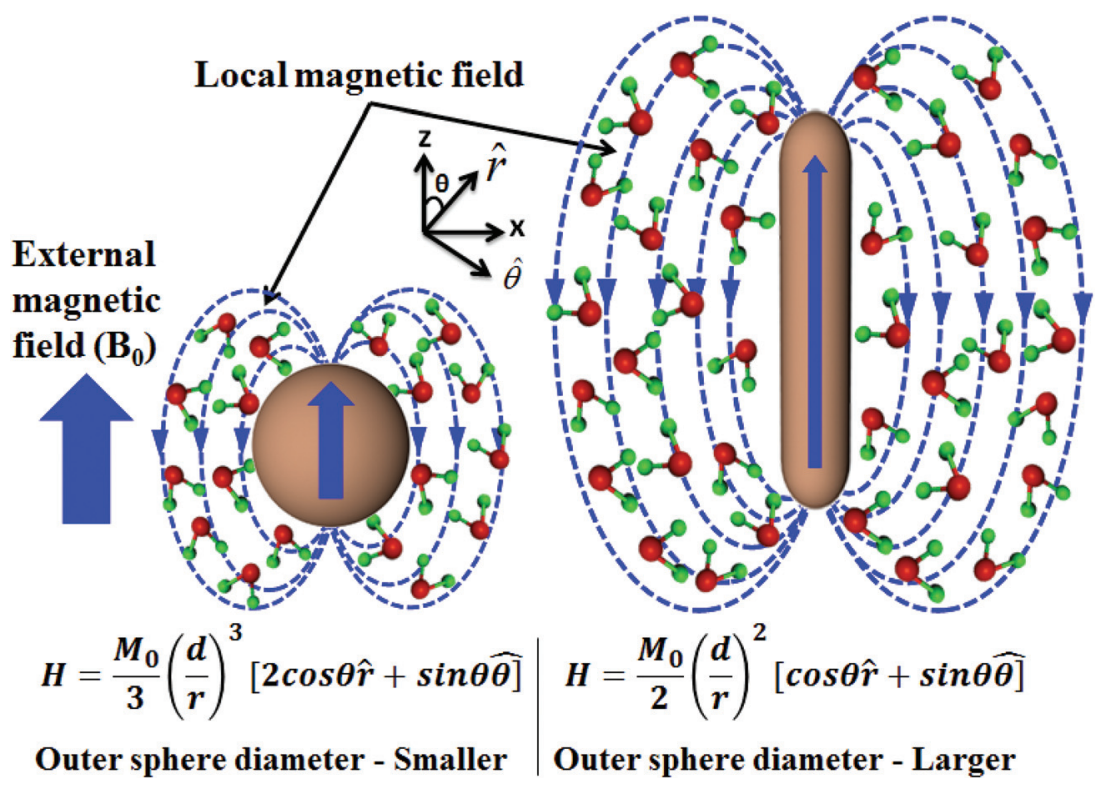

Scheme 2 Schematic representation of the quantum mechanical outer sphere model of $\mathrm{Fe}_{3} \mathrm{O}_{4} \mathrm{NPs}$ and NRs of the same material volume. $H$ is the induced local magnetic field outside NRs and NPs, where $d$ is the effective diameter, $r$ is the distance between the proton spin and the nanostructure being considered and $\theta$ is the inclination angle of the vector joining the proton spin to the nanostructure. In comparison with NPs, the local magnetic field of NRs decreases slowly and hence the strong magnetic field over a larger magnetic volume results in a higher $R_{2}$ relaxivity. 

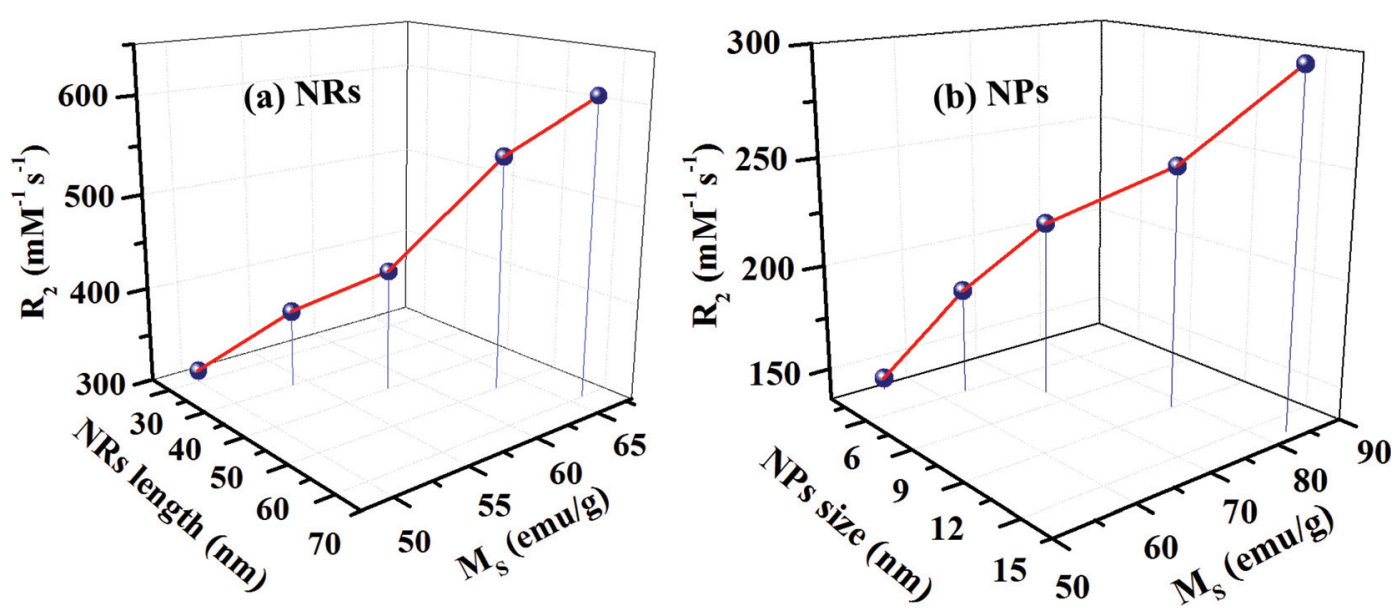

Fig. 8 The variation of $R_{2}$ relaxivity value with: (a) the length and $M_{\mathrm{S}}$ value of nanorods and (b) the diameter and $M_{\mathrm{S}}$ value of nanoparticles. With an increase of nanorods' size, the $R_{2}$ relaxivity values increase linearly from 312 to $608 \mathrm{mM}^{-1} \mathrm{~s}^{-1}$. This linear trend is due to an enhancement of the $M_{\mathrm{S}}$ value as well as the surface area.

It is of interest to note that the highest $R_{2}$ value $608 \mathrm{mM}^{-1} \mathrm{~s}^{-1}$ observed for NRs of length $70 \mathrm{~nm}$ is nearly six times higher than the value reported for the commercial contrast agent (Ferumoxytol and $\left.85 \mathrm{mM}^{-1} \mathrm{~s}^{-1}\right){ }^{23,50}$ In general, the rod shaped morphology offers longer blood circulation times and stronger interaction with tumors in comparison with spherical nanoparticles of equivalent hydrodynamic diameters. ${ }^{31}$ Hence, we believe that nanorods with superior $T_{2}$ weighted contrast properties can improve clinical diagnosis sensitivity to a great extent.

\section{Conclusions}

In summary, we have successfully demonstrated a facile amine mediated reduction process for the synthesis of $\mathrm{Fe}_{3} \mathrm{O}_{4}$ NRs of 30-70 nm length and 4-12 nm diameter. As compared to conventional spherical nanoparticles, $\mathrm{Fe}_{3} \mathrm{O}_{4}$ NRs of similar material volume provide a superior $T_{2}$ contrast effect with 1.5-2 times higher $R_{2}$ value. The enhanced MRI contrast properties of nanorods are attributed to the higher surface area and anisotropic morphology which induces a stronger magnetic field perturbation over a larger volume more effectively for the outer sphere protons. With the increase of the length of $\mathrm{Fe}_{3} \mathrm{O}_{4}$ NRs, the $R_{2}$ value increases sharply from 312 to $608 \mathrm{mM}^{-1} \mathrm{~s}^{-1}$. This increasing trend of $R_{2}$ values with the length of nanorods is due to enhancement of the magnetization value as well as outer sphere surface area. With given biocompatibility and low cytotoxicity, these iron oxide rod shaped structures appear to be promising contrast agents for MRI applications and in future we would like to conduct further in vivo cancer diagnostic studies with such anisotropic functionalized structures.

\section{Acknowledgements}

We gratefully acknowledge the Industrial Research and Consultancy Center (IRCC), IIT Bombay and the Council of Scientific and Industrial Research (CSIR), New Delhi, the Nanomission of the Department of Science and Technology (DST), and the nanotechnology division of the Department of Electronics and Information Technology (DEITY), the Government of India for the financial support of this study. We are thankful to Dr Karthik Ganesan, SRL Diagnostics Pvt Ltd, Lower Parel, Mumbai for providing MRI instrument facilities. M. Aslam would also like to acknowledge a financial support from Prof. Vinayak P. Dravid, the Materials Science and Engineering Department, Northwestern University, Evanston, IL-60201.

\section{References}

1 J. Cheon and J.-H. Lee, Acc. Chem. Res., 2008, 41, 1630-1640.

2 Y.-w. Jun, J.-w. Seo and J. Cheon, Acc. Chem. Res., 2008, 41, 179-189.

3 J.-H. Lee, Y.-M. Huh, Y.-w. Jun, J.-w. Seo, J.-t. Jang, H.-T. Song, S. Kim, E.-J. Cho, H.-G. Yoon, J.-S. Suh and J. Cheon, Nat. Med., 2007, 13, 95-99.

4 N. Lee and T. Hyeon, Chem. Soc. Rev., 2012, 41, 2575-2589.

5 J. R. McCarthy and R. Weissleder, Adv. Drug Delivery Rev., 2008, 60, 1241-1251.

6 E. Terreno, D. D. Castelli, A. Viale and S. Aime, Chem. Rev., 2010, 110, 3019-3042.

7 D. Yoo, J.-H. Lee, T.-H. Shin and J. Cheon, Acc. Chem. Res., 2011, 44, 863-874.

8 A.-H. Lu, E. L. Salabas and F. Schüth, Angew. Chem., Int. Ed., 2007, 46, 1222-1244.

9 J. Gao, H. Gu and B. Xu, Acc. Chem. Res., 2009, 42, 10971107.

10 J.-P. Fortin, C. Wilhelm, J. Servais, C. Ménager, J.-C. Bacri and F. Gazeau, J. Am. Chem. Soc., 2007, 129, 2628-2635.

11 J.-H. Lee, J.-t. Jang, J.-s. Choi, S. H. Moon, S.-h. Noh, J.-w. Kim, J.-G. Kim, I.-S. Kim, K. I. Park and J. Cheon, Nat Nanotechnol., 2011, 6, 418-422. 
12 J. S. Weinstein, C. G. Varallyay, E. Dosa, S. Gahramanov, B. Hamilton, W. D. Rooney, L. L. Muldoon and E. A. Neuwelt, J. Cereb. Blood Flow Metab., 2009, 30, 15-35.

13 H. B. Na, I. C. Song and T. Hyeon, Adv. Mater., 2009, 21, 2133-2148.

14 N. Lee, H. Kim, S. H. Choi, M. Park, D. Kim, H.-C. Kim, Y. Choi, S. Lin, B. H. Kim, H. S. Jung, H. Kim, K. S. Park, W. K. Moon and T. Hyeon, Proc. Natl. Acad. Sci. U. S. A., 2011, 108, 2662-2667.

15 J.-t. Jang, H. Nah, J.-H. Lee, S. H. Moon, M. G. Kim and J. Cheon, Angew. Chem., Int. Ed., 2009, 48, 1234-1238.

16 Z. Li, P. W. Yi, Q. Sun, H. Lei, H. Li Zhao, Z. H. Zhu, S. C. Smith, M. B. Lan and G. Q. Lu, Adv. Funct. Mater., 2012, 22, 2387-2393.

17 Y. Wang, Y. W. Ng, Y. Chen, B. Shuter, J. Yi, J. Ding, S. c. Wang and S. S. Feng, Adv. Funct. Mater., 2008, 18, 308318.

18 Y.-W. Jun, Y.-M. Huh, J.-S. Choi, J.-H. Lee, H.-T. Song, Sungjun, S. Yoon, K.-S. Kim, J.-S. Shin, J.-S. Suh and J. Cheon, J. Am. Chem. Soc., 2005, 127, 5732-5733.

19 R. S. M. Rikken, R. J. M. Nolte, J. C. Maan, J. C. M. van Hest, D. A. Wilson and P. C. M. Christianen, Soft Matter, 2014, 10, 1295-1308.

20 I. Milosevic, H. Jouni, C. David, F. Warmont, D. Bonnin and L. Motte, J. Phys. Chem. C, 2011, 115, 18999-19004.

21 J. Wan, X. Chen, Z. Wang, X. Yang and Y. Qian, J. Cryst. Growth, 2005, 276, 571-576.

22 H. M. Joshi, Y. P. Lin, M. Aslam, P. V. Prasad, E. A. SchultzSikma, R. Edelman, T. Meade and V. P. Dravid, J. Phys. Chem. C, 2009, 113, 17761-17767.

23 K. C. Barick, M. Aslam, Y.-P. Lin, D. Bahadur, P. V. Prasad and V. P. Dravid, J. Mater. Chem., 2009, 19, 7023-7029.

24 M. Aslam, E. A. Schultz, T. Sun, T. Meade and V. P. Dravid, Cryst. Growth Des., 2007, 7, 471-475.

25 K. C. Barick, S. Singh, D. Bahadur, M. A. Lawande, D. P. Patkar and P. A. Hassan, J. Colloid Interface Sci., 2014, 418, 120-125.

26 M. K. Jaiswal, M. De, S. S. Chou, S. Vasavada, R. Bleher, P. V. Prasad, D. Bahadur and V. P. Dravid, ACS Appl. Mater. Interfaces, 2014, 6, 6237-6247.

27 Z. Zhao, Z. Zhou, J. Bao, Z. Wang, J. Hu, X. Chi, K. Ni, R. Wang, X. Chen, Z. Chen and J. Gao, Nat. Commun., 2013, 4, 2266.

28 K. Kattel, J. Y. Park, W. Xu, H. G. Kim, E. J. Lee, B. A. Bony, W. C. Heo, S. Jin, J. S. Baeck, Y. Chang, T. J. Kim, J. E. Bae,
K. S. Chae and G. H. Lee, Biomaterials, 2012, 33, 32543261.

29 S. Huang, J. Liu, D. Liu and Q. Yuan, New J. Chem., 2012, 36, 1335-1338.

30 M.-L. Chen, L.-M. Shen, S. Chen, H. Wang, X.-W. Chen and J.-H. Wang, J. Mater. Chem. B, 2013, 1, 2582-2589.

31 B. Sitharaman, Nanobiomaterials handbook, CRC Press, 2011.

32 J. Mohapatra, A. Mitra, D. Bahadur and M. Aslam, CrystEngComm, 2013, 15, 524-532.

33 A. Mitra, J. Mohapatra, S. S. Meena, C. V. Tomy and M. Aslam, J. Phys. Chem. C, 2014, 118, 19356-19362.

34 A. P. Grosvenor, B. A. Kobe, M. C. Biesinger and N. S. McIntyre, Surf. Interface Anal., 2004, 36, 1564-1574.

35 T. J. Daou, G. Pourroy, S. Bégin-Colin, J. M. Grenèche, C. Ulhaq-Bouillet, P. Legaré, P. Bernhardt, C. Leuvrey and G. Rogez, Chem. Mater., 2006, 18, 4399-4404.

36 L.-Y. Chen, Y.-T. Yin, C.-H. Chen and J.-W. Chiou, J. Phys. Chem. C, 2011, 115, 20913-20919.

37 J.-M. Moon and A. Wei, J. Phys. Chem. B, 2005, 109, 2333623341.

38 S. Mourdikoudis and L. M. Liz-Marzán, Chem. Mater., 2013, 25, 1465-1476.

39 E. Murad and J. L. Bishop, Am. Mineral., 2000, 85, 716-721. 40 M. Chen, Y.-G. Feng, X. Wang, T.-C. Li, J.-Y. Zhang and D.-J. Qian, Langmuir, 2007, 23, 5296-5304.

41 J. K. Armstrong, R. B. Wenby, H. J. Meiselman and T. C. Fisher, Biophys. J., 2004, 87, 4259-4270.

42 P. K. Kandel, L. P. Fernando, P. C. Ackroyd and K. A. Christensen, Nanoscale, 2011, 3, 1037-1045.

43 T. Xia, M. Kovochich, M. Liong, H. Meng, S. Kabehie, S. George, J. I. Zink and A. E. Nel, ACS Nano, 2009, 3, 32733286.

44 G. Joaquín and S. Gloria, J. Phys.: Condens. Matter, 2004, 16, R145.

45 W. Friedrich, J. Phys.: Condens. Matter, 2002, 14, R285.

46 J. Mohapatra, A. Mitra, D. Bahadur and M. Aslam, J. Alloys Compd., 2015, 628, 416-423.

47 J. Wan, Y. Yao and G. Tang, Appl. Phys. A, 2007, 89, 529532.

48 H. Sun, B. Chen, X. Jiao, Z. Jiang, Z. Qin and D. Chen, J. Phys. Chem. C, 2012, 116, 5476-5481.

49 J. F. Schenck, Med. Phys., 1996, 23, 815-850.

50 S. Xuan, Y.-X. J. Wang, J. C. Yu and K. Cham-Fai Leung, Chem. Mater., 2009, 21, 5079-5087. 